\title{
Virulence Determinants of Candida Infections in High Risk Neonates and Infants in a Tertiary Hospital of North India
}

\author{
Sarver Jahan ${ }^{1}$, Mohd Waseeque Khan ${ }^{2}{ }^{1}$ Abida Malik ${ }^{3}$, Nazish Fatima ${ }^{4}$ \\ ${ }^{1,3,4}$ Department of Microbiology JNMC, AMU, Aligarh, India \\ ${ }^{2}$ Department of Paediatrics ELMCH, Lucknow, India
}

\begin{abstract}
Introduction: Candida spp. are considered as opportunistic pathogens because they posses many virulence factors which contributes in the pathogenesis of Candida infections. The virulence of Candida spp. is attributed to certain factors like biofilm formation, and the production of hydrolytic enzymes. Objective: To study the virulence factors of Candida infections among high risk neonates and infants. Materials and methods: Samples were collected aseptically from 128 high risk neonates and infants. They were cultured and identified by standard microbiological techniques and their virulence factors such as biofilm formation was demonstrated by tube method, egg yolk agar for proteinase activity, bovine serum albumin agar for phospholipase activity and sabouraud dextrose agar with sheep blood for haemolytic activity. Results: All the virulence markers were significantly associated with the development of candidiasis among neonates and infants. However among all these factors biofilm and hemolysin production were found to be highly significant. Biofilm formation in this study was more often found in the non albicans Candida spp. (95\%) as compared to Candida albicans. $C$. tropicalis produces stronger biofilms $(40 \%$ were $3+\& 10 \%$ were $4+)$ than $C$. albicans $(10.3 \%$ produced $3+$ and $4+$ biofilms). Phospholipase activity was noted in $34.7 \%$ of Candida spp., Maximum phospholipase production was seen in NAC spp. (65\%) as compared to $C$. albicans (13.6\%). Proteinase activity was seen $38.8 \%$ of Candida isolates. Conclusion: As non-albicans Candida infections are on the rise, microbiology laboratories should go for complete identification of all yeast isolates and their virulence.
\end{abstract}

Keywords: Virulence factor; Non Candida species, Neonates and Infants

\section{Introduction}

Candidiasis is the commonest fungal disease found in human affecting mucosa, skin, nails and internal organs. Premature infants are a high risk group notably due to their undeveloped immune systems. Candida spp. may be acquired vertically from the mother, or horizontally in the neonatal intensive care unit (1).

Candida spp. are considered as opportunistic pathogens because they posses many virulence factors which contributes in the pathogenesis of Candida infections. The virulence of Candida spp. is attributed to certain factors like adherence, biofilm formation, and the production of tissuedamaging extracellular hydrolytic enzymes (2, 3). Extracellular hydrolytic enzymes like phospholipase and proteinase are important for colonization and invasion of host tissue (4). The most relevant virulence factors for Candida spp. are as follows:

1) Adhesion: Adherence of Candida spp. to a wide range of tissue types and inanimate surfaces is essential in the early stages of colonization and tissue invasion.

2) Hyphal dimorphism: Yeast hyphal dimorphism status of Candida plays an important role as a virulence factor.

3) The cell surface hydrophobicity: The hydrophobicity of the cell surface of Candida albicans plays an important role in the adhesion of the organism to eukaryotic cells and inert surfaces. The mannans ( glycoproteins present on the cell surface of Candida albicans ) contribute to the virulence of Candida albicans mainly by affecting the yeast cell surface hydrophobicity, leading to change in adherence to host tissues.
4) Enzymes: The extracellular hydrolytic enzymes including secreted aspartyl proteinase and phospholipases degrade immunoglobulins and proteins of the extracellular matrix; they also inhibit the phagocytosis of polymorphonuclear neutrophils and induce inflammatory reactions.

5) The phenotypic switching phenomena: C. albicans is capable of high frequency, reversible phenotypic switching. This property helps the yeast adapt to its diverse locations as a commensal or opportunistic pathogen (5) and to assists the fungus in evading the host's defence mechanisms (6).

\section{Materials and Methods}

The present study was carried out in the Department of Microbiology J. N. Medical College, AMU, on 128 high risk neonates and infants admitted in the NICU and in the HDU of Department of Paediatrics, during the period of one and half years from 2013 to 2014. Various clinical specimens including blood, tracheobronchial aspirate, oral swab, ear swab, CSF and urine were collected.

Specimens like endotracheal aspirate, urine, oral swab etc., were subjected to direct microscopy by making a lactophenol cotton blue(LCB) mount and /or a Gram stained smear. The samples were inoculated on to Sabouraud's dextrose agar as the main isolation medium. For blood samples, Approximately 1 to $2 \mathrm{ml}$ of blood was collected under aseptic precautions and inoculated in biphasic brain heart infusion medium. The culture medium was incubated at $37^{\circ} \mathrm{C}$ for a week or longer if required. Subculture was done on third, fifth, and seventh day. All the Candida 


\section{International Journal of Science and Research (IJSR) \\ ISSN (Online): 2319-7064 \\ Index Copernicus Value (2015): 78.96 | Impact Factor (2015): 6.391}

isolates were subjected to germ tube test using normal human serum. Colonies were identified up to the species level on the basis of colony characteristics, morphology on Corn meal agar, growth on Hi- CHROME Candida agar, carbohydrate fermentation, and assimilation patterns $(7,8)$.

\section{Detection of Various Virulence Factors}

\section{1) Detection of Biofilm formation}

Biofilm production of isolates was demonstrated with a slight modification method, as described by Hassan et al.,(9). Biofilm formation was positive when a blue visibly adherent layer lined the wall and bottom of the tube and was scored as weak $(1+)$, moderate $(2+$ or $3+)$ or strong $(4+)$, based on amount of biofilm production. Each isolate was tested at least three times and read independently by two different observers. Biofilm producer Staphylococcus epidermidis ATCC 35984 and non-biofilm producer $S$. epidermidis ATCC 12228 were used as the positive and negative controls, respectively.

2) Detection of phospholipase, haemolysin and proteinase activity:

Preparation of the yeast suspensions: Yeast suspensions were prepared from the yeast isolates included in the study to evaluate phospholipase, proteinase and hemolytic activity. First, a small amount of stock culture was inoculated on Sabouraud dextrose agar (SDA) (Oxoid) containing chloramphenicol by using a sterile loop and incubated at 37 ${ }^{\circ} \mathrm{C}$ for 24-48 h. Then the yeasts were harvested and suspended in sterile phosphate buffered solution (PBS) at turbidity equal to optical density (OD) of 0.5 McFarland. The final suspension was adjusted to contain $1 \times 10^{7}$ yeast cells $/ \mathrm{ml}$.

Determination of phospholipase activity: To determine phospholipase activity, the egg yolk agar method of Price et al., (10) which was modified by Samaranayake et al., (11), was employed. The presence of enzyme activity was determined by the formation of a precipitation zone around the yeast colonies. Phospholipase activity $(\mathrm{Pz})$ was calculated by dividing the diameter of the colony by the diameter of the colony plus precipitation zone. The $\mathrm{Pz}$ was scored as follows:A PZ of 1.0 was evaluated as negative (-), $0.99-0.9$ as weak $(+), 0.89-0.8$ as mild $(++), 0.79-0.7$ as relatively strong $(+++)$ and $<0.69(++++)$ as very strong positive.

Determination of hemolytic activity: Haemolysin activity of Candida spp. was detected by blood agar plate assay as described by Manns et al., (12).

Determination of proteinase activity:To determine proteinase activity, bovine-serum albumin agar defined by Staib (13) was employed.

Enzyme activity (Prz) was calculated according to the method described by Price et al. Prz was scored as follows: $\operatorname{Prz}=1$, negative proteinase activity, $\operatorname{Prz}=0.99-0.9$ as weak $(+), \operatorname{Prz}=0.89-0.8$ as mild $(++), \operatorname{Prz}=0.79-0.7$ as relatively strong $(+++)$ and $\operatorname{Prz}<0.69(++++)$ as very strong positive.

Detection of Pseudohyphae Formation: The percentage of cells in pseudohyphae form, against blastospores, was determined by microscopy counting after $2 \mathrm{~h}$ of cell growth in a liquid medium containing equal volumes of RPMI 1640 (Sigma) and fetal bovine serum . In this, 100 cells per field were examined. Each experiment was conducted in triplicate (14).

\section{Results}

The present study was conducted to determine the virulence of Candida infections in high risk neonates and infants. One hundred and twenty eight high risk neonates and infants were included in the study.

Table 1: Prevalence of Candida infection among neonates and infants in the study group, $(\mathrm{n}=128)$

\begin{tabular}{|c|c|c|}
\hline Isolate & No. of cases & $\%$ \\
\hline Candida spp. isolated & 39 & 30.5 \\
\hline No Candida spp. isolated & 89 & 69.5 \\
\hline Total & 128 & 100 \\
\hline
\end{tabular}

Table 1 show the prevalence of infection by Candida species in high risk neonates and infants included in the study. It can be seen that out of a total of 128 patients, Candida could be isolated in $39(30.5 \%)$ cases.

Table 2

\begin{tabular}{|c|c|c|c|c|}
\hline $\begin{array}{c}\text { Clinical } \\
\text { diagnosis }\end{array}$ & $\begin{array}{c}\text { No. of } \\
\text { patients }\end{array}$ & Sample & \multirow{2}{*}{ No. of isolates } & $\%$ \\
\hline \multirow{2}{*}{ Septicaemia } & 25 & Blood(23) & \multirow{2}{*}{29} & \multirow{2}{*}{59.2} \\
\cline { 3 - 4 } & & blood (3)+urine(3)* & & \\
\cline { 3 - 4 } & 5 & Oral swab & $5+3 *=8$ & 16.3 \\
\hline Oral thrush & 5 & Urine & $4+3 *=7$ & 14.3 \\
\hline UTI & 2 & Ear swab & 2 & 4.1 \\
\hline CSOM & 2 & CSF & 2 & 4.1 \\
\hline Meningitis & 1 & Endotracheal aspirate & 1 & 2 \\
\hline Pneumonia & 39 & & 49 & 100 \\
\hline Total & & &
\end{tabular}

Distribution of Candida isolates in relation to clinical diagnosis in neonates and infants with candidiasis *3 urine and 3 oral swab Candida isolates were from septicaemia patients.

Table 2 shows the distribution of Candida isolates in relation to clinical diagnosis from neonates and infants with candidiasis. The maximum number of Candida isolates were found from patients with septiceamia $(59.2 \%)$ followed by cases of oral thrush $(16.3 \%)$ and cases of urinary tract infections $(14.3 \%)$.

Table 3: Candida spp. isolated from patients in the study group, $(\mathrm{n}=49)$

\begin{tabular}{|c|c|c|c|}
\hline \multicolumn{2}{|c|}{ Candida spp. } & $\begin{array}{c}\text { No. of } \\
\text { isolates }\end{array}$ & \multicolumn{2}{c|}{$\%$} \\
\hline Candida albicans (29) & C.albicans & 29 & 59.2 \\
\hline \multirow{4}{*}{$\begin{array}{c}\text { Nonalbicans Candida } \\
(20)\end{array}$} & C.tropicalis & 7 & 14.3 \\
\cline { 2 - 4 } & C.parapsilosis & 6 & 12.2 \\
\cline { 2 - 4 } & C.guilliermondii & 3 & 6.2 \\
\cline { 2 - 4 } & C.glabrata & 2 & 4.1 \\
\cline { 2 - 4 } & C.dubliniensis & 1 & 2 \\
\cline { 2 - 4 } & C.krusei & 1 & 2 \\
\hline Total & & 49 & 100 \\
\hline
\end{tabular}

\section{Volume 6 Issue 1, January 2017




\section{International Journal of Science and Research (IJSR) ISSN (Online): 2319-7064 \\ Index Copernicus Value (2015): 78.96 | Impact Factor (2015): 6.391}

Table 3 depicts the distribution of various Candida spp. isolated from patients in the study group.

Candida albicans (59.2\%) was the most common species isolated from neonates and infants suffering from candidiasis while non albicans Candida were $40.8 \%$. In non albicans Candida, Candida tropicalis (14.3\%) was most frequently isolated spp. followed by Candida parapsilosis (12.2\%), Candida guilliermondii (6.2\%), Candida glabrata (4\%), Candida krusei (2\%) and Candida dubliniensis (2\%)

Table 4: Correlation of various virulence markers among different species isolated from patients, $(n=39)$

\begin{tabular}{|c|c|c|c|c|c|c|c|}
\hline Candida spp. & & No. of cases & Biofilm & Pseudohyphae & Hemolysin & Phospholipase & Proteinase \\
\hline C. albicans & \multirow{8}{*}{ 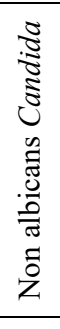 } & 22 & $17(77.3 \%)$ & $5(22.7 \%)$ & $22(100 \%)$ & $4(18.2 \%)$ & $3(13.6 \%)$ \\
\hline C. tropicalis & & 5 & 5 & 2 & 5 & 3 & 3 \\
\hline C. parapsilosis & & 5 & 3 & 2 & 5 & 2 & 3 \\
\hline C. guilliermondii & & 3 & 3 & - & 3 & 2 & 2 \\
\hline C. glabrata & & 2 & 2 & - & 2 & 2 & 2 \\
\hline C. krusei & & 1 & 1 & 1 & 1 & 1 & 1 \\
\hline C. dubliniensis & & 1 & 1 & - & 1 & 1 & 1 \\
\hline Total & & 17 & $15(88.2 \%)$ & $5(29.4 \%)$ & $17(100 \%)$ & $11(64.7 \%)$ & $12(70.6 \%)$ \\
\hline & & 39 & $33(84.6 \%)$ & $10(25.6 \%)$ & $39(100 \%)$ & $15(38.5 \%)$ & $15(15.8 \%)$ \\
\hline
\end{tabular}

Figures in parenthesis indicate percentage

Table 4 exhibit the correlation of various virulence markers among different species of candidiasis patients.

It was observed that most common virulence factors were hemolysin $(100 \%)$ and biofilm production $84.6 \%$.

As it was evident from the table that proteinase $(70.6 \%)$ and phospholipase production (64.7\%) was most commonly produced in patients infected by non albicans Candida spp.as compared to C.albicans.

It was noted that all pseudohyphae producing strains also produced phospholipase.
Table 5: Presence of various virulence markers among Candida isolates

\begin{tabular}{|l|l|l|l|}
\hline \multicolumn{1}{|c|}{ Virulence Factor } & Positive & Negative & \multicolumn{1}{c|}{$P^{\prime}$ 'value } \\
\hline Biofilm formation & 43 & 6 & $0.0001(\mathrm{~S})$ \\
\hline Phospholipase production & 17 & 32 & $0.004(\mathrm{~S})$ \\
\hline Proteinase production & 19 & 30 & $0.042(\mathrm{~S})$ \\
\hline Hemolysin production & 49 & 0 & $0.0001(\mathrm{~S})$ \\
\hline Pseudohyphae formation & 10 & 39 & $0.0001(\mathrm{~S})$ \\
\hline
\end{tabular}

Table 5 depicts the various virulence markers studied among candidiasis patients.

All the virulence markers were significantly present in the Candida isolates among neonates and infants. However, among all the factors, biofilm and hemolysin production were found to be highly significant $(\mathrm{p}<0.01)$.

Table 6: Different scores of biofilm production of various Candida species $(n=49)$

\begin{tabular}{|c|c|c|c|c|c|c|c|}
\hline \multirow[t]{2}{*}{ Candida spp. } & \multirow{3}{*}{$\stackrel{\vartheta}{\sim}$} & \multicolumn{5}{|c|}{ Scores of biofilm formation } & \multirow[b]{2}{*}{ Total } \\
\hline & & - & + & ++ & +++ & ++++ & \\
\hline C.albicans $(n=29)$ & & $5(17.2)$ & $10(34.4)$ & $8(27.5)$ & $3(10.3)$ & $3(10.3)$ & 29 \\
\hline C.tropicalis & $\Sigma$ & - & $3(42.8)$ & - & $3(42.8)$ & $1(14.1)$ & 7 \\
\hline C.parapsilosis & : & $1(16.6)$ & $1(16.6)$ & - & $4(66.7)$ & - & 6 \\
\hline C.guilliermondii & క & - & $1(33.3)$ & $2(66.7)$ & - & - & 3 \\
\hline C.glabrata & $\bigcup_{1}^{0}$ & - & $1(50)$ & - & - & $1(50)$ & 2 \\
\hline C.dubliniensis & స్ & - & - & - & $1(100)$ & - & 1 \\
\hline C.krusei & $\frac{0}{0}$ & - & $1(100)$ & - & - & - & 1 \\
\hline Total & $\stackrel{\bar{\sigma}}{=}$ & $1(5)$ & $7(35)$ & $2(10)$ & $8(40)$ & $2(10)$ & 20 \\
\hline Total & $\overline{0}$ & $6(12.2)$ & $17(34.7)$ & $10(20.5)$ & $11(22.4)$ & $5(10.2)$ & 49 \\
\hline
\end{tabular}

Figures in parenthesis indicate percentage

Table 6 shows the pattern of biofilm formation exhibited by different Candida isolates.

It was observed that the maximum number of isolates have score of $1+(34.7 \%)$ followed by $3+(22.4 \%)$ and $2+(20.5 \%)$ score of biofilm formation.

Almost all the nonalbicans Candida spp. were positive for biofilm formation (95\%) as compared to C. albicans (82.7\%). In non albicans Candida spp. 8(40\%) and 2(10\%) showed $3+$ and $4+$ biofilm formation respectively. However only $3(10.3 \%)$ C. albicans produced $3+$ and $4+$ biofilm.
Table 7: Comparison of biofilm production by Candida spp. isolates obtained from the blood stream and from other sites in the study group

\begin{tabular}{|c|c|c|c|c|}
\hline \multirow{2}{*}{ Candida spp. } & \multirow{2}{*}{$\begin{array}{c}\text { No. of } \\
\text { isolates }\end{array}$} & \multicolumn{2}{|c|}{$\begin{array}{l}\text { Isolates positive for } \\
\text { biofilm formation }\end{array}$} & \multirow{2}{*}{ P value } \\
\cline { 3 - 4 } & & Blood stream & Other sites & \\
\hline Candida albicans & 29 & $12(41.4)$ & $17(58.6)$ & $0.29(\mathrm{NS})$ \\
\hline Non albicans Candida & 20 & $17(85)$ & $3(15)$ & $0.0001(\mathrm{~S})$ \\
\hline Total & 49 & 29 & 20 & \\
\hline
\end{tabular}

Figures in parenthesis indicate percentage

Table 7 (figure 2) depicts the comparison of biofilm formation between Candida albicans with nonalbicans Candida isolates with respect to the site of collection either blood stream or from other sites. 


\section{International Journal of Science and Research (IJSR) \\ ISSN (Online): 2319-7064 \\ Index Copernicus Value (2015): 78.96 | Impact Factor (2015): 6.391}

As is evident from the table that biofilm formation among non albicans Candida isolates was more significantly

associated with blood stream infections as compared to other site infections from where samples were collected.

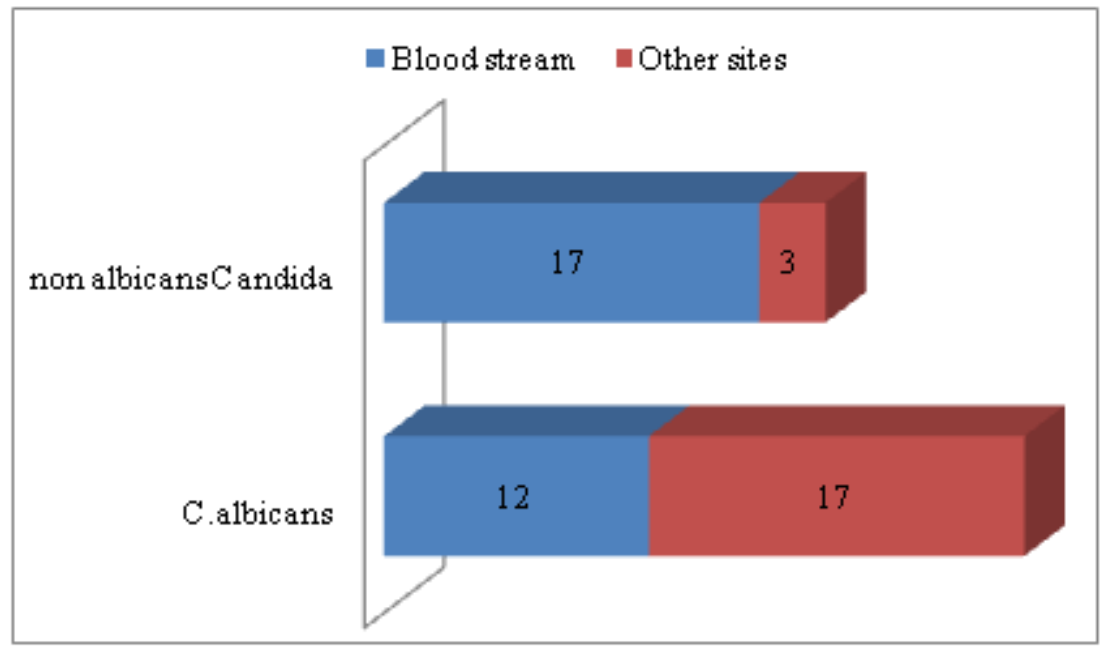

Figure 1: Comparison of biofilm production by Candida spp. isolates obtained from the blood stream and from other sites in the study group

Table 8: Phospholipase ( $\mathrm{Pz})$ value of different Candida spp.

\begin{tabular}{|c|c|c|c|c|c|c|c|}
\hline \multirow{2}{*}{\multicolumn{2}{|c|}{ Candida spp. }} & \multicolumn{5}{|c|}{ Phospholipase (Pz) value } & \multirow[b]{2}{*}{ Tota } \\
\hline & & - & + & ++ & +++ & ++++ & \\
\hline C.albicans $(n=$ & & $25(86.2)$ & $2(6.8)$ & $2(6.8)$ & - & - & 29 \\
\hline C.tropicalis & \multirow{8}{*}{ 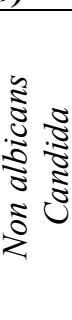 } & $3(42.8)$ & - & $1(14.2)$ & $1(14.2)$ & $2(28.4)$ & 7 \\
\hline C.parapsilosis & & $4(66.7)$ & $1(16.6)$ & - & $1(16.6)$ & - & 6 \\
\hline C.guilliermondii & & - & $1(33.3)$ & $2(66.7)$ & - & - & 3 \\
\hline C.glabrata & & - & - & - & $1(50)$ & $1(50)$ & 2 \\
\hline C.dubliniensis & & - & $1(100)$ & - & - & - & 1 \\
\hline C.krusei & & - & - & - & $1(100)$ & - & 1 \\
\hline Total & & $7(35)$ & $3(15)$ & $3(15)$ & $4(20)$ & $3(15)$ & 20 \\
\hline Total & & $32(65.3)$ & $5(10.2)$ & $5(10.2)$ & $4(8.1)$ & $3(6.2)$ & 49 \\
\hline
\end{tabular}

Figures in parenthesis indicate percentage

Table 8 depicts phospholipase production by different Candida species causing infection among neonates and infants.

Most of the isolates showed lower range (i.e. 1+ and 2+) production of phospholipase
Out of 20 non albicans Candida isolates, 13(65\%) showed phospholipase production while only $4(13.6 \%)$ of $C$. albicans were phospholipase producer. In nonalbicans Candida isolates, higher range (i.e. $3+$ and $4+$ ) of phospholipase production was observed, vis -a-vis lower range phospholipase (i.e. $1+\& 2+$ ) production was noted among $C$. albicans isolates.

Table 9: Proteinase production among different Candida species.

\begin{tabular}{|c|c|c|c|c|c|c|c|}
\hline \multirow{2}{*}{\multicolumn{2}{|c|}{ Candida spp. }} & \multicolumn{5}{|c|}{ Proteinase score } & \multirow[b]{2}{*}{ Total } \\
\hline & & - & + & ++ & +++ & ++++ & \\
\hline \multicolumn{2}{|c|}{ C.albicans $(n=29)$} & 24 & 1 & 2 & 2 & - & 29 \\
\hline C.tropicalis & \multirow{7}{*}{ 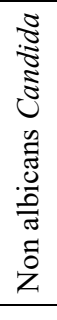 } & 3 & - & 1 & 2 & 1 & 7 \\
\hline C.parapsilosis & & 3 & 1 & 1 & 1 & - & 6 \\
\hline C.guilliermondii & & - & 2 & 1 & - & - & 3 \\
\hline C.glabrata & & - & - & 1 & 1 & - & 2 \\
\hline C.dubliniensis & & - & 1 & - & - & - & 1 \\
\hline C.krusei & & - & - & - & 1 & - & 1 \\
\hline Total & & $6(30)$ & $4(20)$ & $4(20)$ & $5(25)$ & $1(5)$ & 20 \\
\hline Total & & $30(61.2)$ & $5(10.2)$ & $6(12.2)$ & $7(14.3)$ & $1(2.1)$ & 49 \\
\hline
\end{tabular}

Figures in parenthesis indicate percentage

Table 9 depicts the proteinase production by different Candida spp. isolated from neonates and infants. It was observed that the maximum number of isolates had a score of $3+$ followed by $2+$ and $1+$ proteinase production.
Only $17.2 \% \quad$ C.albicans isolates showed proteinase production. However among non albicans Candida isolates $70 \%$ isolates showed proteinase production. 


\section{International Journal of Science and Research (IJSR) \\ ISSN (Online): 2319-7064}

Index Copernicus Value (2015): 78.96 | Impact Factor (2015): 6.391

Table 10: Hemolysin production of various Candida species

\begin{tabular}{|c|c|c|c|c|}
\hline \multirow{2}{*}{\multicolumn{2}{|c|}{ Candida spp. }} & \multicolumn{3}{|c|}{ Hemolysin production } \\
\hline & & Positive & Negative & Total \\
\hline C.albicans & & $29(100)$ & - & 29 \\
\hline C.tropicalis & \multirow{6}{*}{ 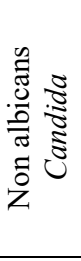 } & $7(100)$ & - & 7 \\
\hline C.parapsilosis & & $6(100)$ & - & 6 \\
\hline C.guilliermondii & & $3(100)$ & - & 3 \\
\hline C.glabrata & & $2(100)$ & - & 2 \\
\hline C.dubliniensis & & $1(100)$ & - & 1 \\
\hline C.krusei & & $1(100)$ & - & 1 \\
\hline Total & & 49 & - & 49 \\
\hline
\end{tabular}

Figures in parenthesis indicate percentage

Table 10 shows the production of hemolysin by various Candida species among neonates and infants.

$100 \%$ of Candida albicans as well as other non albicans Candida isolates produced hemolysin.

\section{Discussion}

The present study was conducted in the Department of Microbiology, Jawaharlal Nehru Medical College, AMU, Aligarh from February 2013 to October 2014. A total of 128 children suffering from various clinical diseases, categorized into different predefined high risk groups were included in the study to determine the profile of Candida infections with respect to the predominant species, pathogenic characteristics in high risk neonates and infants.

The most commonly identified patient group in this study were neonates and infants with septicaemia (69.6\%), followed by patients with oral thrush $(10.9 \%)$, urinary tract infection $(9.4 \%)$. The other group included patient with pneumonia $(3.1 \%)$, meningitis $(3.1 \%)$ and ear infection (3.9\%). Thus, the study group compromised of a varied patient population with different clinical diagnosis.

Multiple samples from different sites were also collected. The most frequently collected specimens were blood (72.8\%), followed by urine (9.4\%). The next most common sample collected was oral swab (9.4\%). Other relevant specimens included the endotracheal aspirate, CSF and ear swab.

Overall the rate of Candida isolation from various specimens in our study group was $30.5 \%$. C.albicans formed the largest group (59.2\%) of Candida species isolated in this study. Jarvis (15) and Pfaller (16) had reported 50 to $70 \%$ Candida albicans isolation, Roilides et al (17) 65\%, Ariff S (18) $55 \%$ of isolation in their respective studies. Indian studies which reported almost similar findings were $\mathrm{S}$ Narain (53.3\%)(19), Kaur R (50\%)(20). However, Kotwal A et al (21) noted a much higher prevalence of C.albicans (78.1\%).

Although $C$. albicans was the most commonly isolated species $(59.2 \%)$ in our study non albicans Candida (NAC) also substantially caused candidiasis. The next most common isolate, C. tropicalis formed $14.3 \%$ of the total isolates.
Candida spp. have various virulence factors that facilitate proliferation, they may result in adhesion to the epithelium and invasion of the host tissue. Biofilm formation, hemolysin production and pseudohyphae formation also plays an essential role in the pathogenicity of Candida spp. The extracellular hydrolytic enzymes including secreted aspartyl proteinase and phospholipases also play an important role in candidal growth. Early detection of virulence factors by Candida is useful in clinical decision making.

In the present study, we observed that all the isolates (100\%) produced hemolysin, 43 isolates $(87.8 \%)$ showed biofilm formation, 19 isolates $(38.8 \%)$ showed proteinase production, phospholipase production was formed in 17 (34.7\%) and pseudohyphae formation by 10 (20.4\%) Candida isolates.

All the virulence markers were significantly associated with the development of candidiasis among neonates and infants. However among all these factors biofilm and hemolysin production were found to be highly significant $(\mathrm{p}<0.001)$.

Biofilm is a community of microorganisms and their extracellular polymers that are attached to a surface. The ability to form biofilms is associated with the pathogenecity and should be considered as an important virulence determinant during candidiasis.

Biofilm formation in this study was more often found in the non albicans Candida spp. (95\%) as compared to Candida albicans. It was also observed that the maximum no. of isolates have scored $1+$ biofilm formation followed by $3+$ score. While among non albicans Candida spp. 3+ grade was more frequent, this suggest that in high risk neonates and infants, non albicans Candida spp. were more virulent. This finding was in accordance with the study done by Shin $\mathrm{JH}$ et al (22).

We observed the combined biofilm positivity of bloodstream isolates of all the non-albicans Candida species was significantly higher than for isolates from other sites. This finding was similar to the study done by Kaur R et al (20), who observed that $60.78 \%$ of isolates of NAC spp. produced biofilm in comparison to $39.21 \%$ of $C$. albicans producing lower slime.

Our data also suggests that $C$. tropicalis produces stronger biofilms $(40 \%$ were $3+\& 10 \%$ were $4+)$ than $C$. albicans ( $10.3 \%$ produced $3+$ and $4+$ biofilms).

The production of haemolysin plays an important role in virulence. Haemolysins are proteins produced by microorganisms to destroy red blood cells. Iron, an inorganic element, is essential for the development of microorganisms, including yeasts, and the ability to obtain this element is essential for the establishment of an infectious process (12). In our study, all the isolates were able to express hemolytic activity. Manns et al. (12), demonstrated that $C$. albicans produced hemolytic activity and Luo et al. (23) observed that NAC species are capable of producing one or more types of hemolysins in vitro with differences among species. 


\section{International Journal of Science and Research (IJSR) \\ ISSN (Online): 2319-7064 \\ Index Copernicus Value (2015): 78.96 | Impact Factor (2015): 6.391}

The other important hydrolytic enzymes are proteinase and phospholipases. The aspartic proteinase (Sap) isoenzymes are also responsible for the proteinase activity of $C$. albicans. Sap proteins have also been described in $C$. tropicalis, C. parapsilosis and C. guilliermondii (24). Several studies have demonstrated a relationship between an increase in the synthesis and activity of extracellular hydrolytic enzymes and an increase in the pathogenic potential of the yeasts, leading to clinical signs of severe candidiasis $(25,26)$.

In our study phospholipase activity was noted in $34.7 \%$ of Candida spp., Maximum phospholipase production was seen in NAC spp. (65\%) as compared to C. albicans (13.6\%). Among NAC C. tropicalis (57.1\%) showed maximum phospholipase production, which was similar to the observation of Thangam et al (27) and Deorukhkar et al.,(4). Changdeo S. Aher, (28) studied phospholipase activity in (58.1) isolates and found phospholipase production was maximum in $C$. albicans followed by $C$. glabrata and $C$. tropicalis. Samaranayake et al, (11) reported no production of phospholipase by $C$. tropicalis. The variation in different strains or the difference in the method of media preparation may be the reason for discrepancy observed by different workers in the phospholipase activity of the NAC spp. Also, Phospholipase production was observed to be at higher range by NAC as compared to by $C$. albicans isolates. As phospholipase helps in host tissue invasion, it may be one of the important virulence factor utilized by NAC to cause BSIs.

Proteinase activity was seen $38.8 \%$ of Candida isolates in our study. This finding was in accordance with Changdeo S. Aher (28), who observed $37.8 \%$ of proteinase production in Candida isolates. We observed that only $17.2 \%$ C. albicans isolates showed proteinase production. However among non albicans Candida isolates $70 \%$ isolates showed proteinase production. Our findings were similar to Mohandas V (29). Who also reported that non-albicans Candida spp. produced more proteinase than $C$. albicans strains.

C. albicans reversibly converts from unicellular yeast cells to either pseudohyphal or hyphal growth, a morphogenesis phenomenon (creating a transition between unicellular yeast cells and a filamentous growth form). C. albicans and $C$. dubliniensis form both types of filamentous growth, indicating that these yeasts are capable of growing isotropically (yeast) or apically (hyphal and pseudohyphal). The growth of hyphae, a virulence mechanism, plays an important function in tissue invasion and resistance to phagocytosis (30). We found $22.4 \%$ isolates showed pseudohyphae formation. The morphogenetic change from the yeast to hyphal form is involved in fungal tissue invasion and penetration.

\section{Conclusion}

The incidence of Candida infection among a total of 128 patients in the present study was $30.5 \%$. C.albicans $(59.2 \%)$ was the most common species isolated from all the specimens. The second most common Candida spp. after C.albicans to cause candiasis was C.tropicalis $(1.43 \%)$ followed by C.parapsilosis (12.2\%), C.guilliermondii
(16.2\%), C.glabrata (4\%), C.dubliniensis (2\%) and C.kursei $(2 \%)$.

On studying the various virulence factors produced by the Candida isolates, we observed that all the isolates (100\%) produced hemolysin, $87.8 \%$ formed biofilm, $38.8 \%$ produced proteinase enzyme, $34.7 \%$ produced phospholipase enzyme while $20.4 \%$ showed pseudohyphae formation.

All the virulence markers were significantly associated with the development of candidiasis. However, biofilm formation and hemolysin production were found to be highly significant $(\mathrm{p}<0.01)$.

We found biofilm formation was more related to NAC then C.albicans. We observed that the biofilm formation among NAC was more significantly associated with blood stream infections as compared to other site infections. Among NAC, C.tropicalis was found to produce stronger biofilms as compared to C.albicans. C.tropicalis was the commonest NAC producing biofilms.

All the Candida isolates expressed hemolytic activity. Hemolysin production by C.albicans had positive correlation with hemolysin production by NAC species and was statistically significant $(\mathrm{p}<0.01)$.

In this study phospholipase activity was noted in $34.7 \%$ of Candida species. Phospholipase production was more commonly seen in NAC (65\%) as compared to C.albicans $(13.6 \%)$ also phospholipase production was observed to be in higher range in NAC and in lower range in C.albicans isolates.

While observing proteinase enzyme production, we found $38.8 \%$ of Candida isolates to be proteinase producers. Also, more NAC (70\%) expressed proteinase activity as compared to C.albicans (17.2\%). In this work we found $22.4 \%$ of Candida isolates were forming Pseudohyphae.

As non-albicans candida infections are on the rise, microbiology laboratories should go for complete identification of all yeast isolates.

Candida is significantly rising. Non albicans candidiasis should be considered when initiating antifungal prophylaxis as they possess a different antifungal susceptibility spectrum from C. albicans.

\section{References}

[1] Ruiz-Diez B, Martinez V, Alvarez M, RodriguezTudela JL, Martinez-Suarez JV. Molecular tracking of Candida albicans in a neonatal intensive care unit: longterm colonizations versus catheter-related infections. J Clin Microbiol. 1997 Dec;35(12):3032-3036.

[2] Melek İNCI, Mustafa Altay ATALAY, Ayşe Nedret $\mathrm{KOÇ}$ et al. Investigating virulence factors of clinical Candida isolates in relation to atmospheric conditions and genotype. Turk J Med Sci 2012; 42(Sup.2): 14761483 . 


\section{International Journal of Science and Research (IJSR) \\ ISSN (Online): 2319-7064 \\ Index Copernicus Value (2015): 78.96 | Impact Factor (2015): 6.391}

[3] Sardi JCO, Scorzoni L, Bernardi T et al. Candida species: current epidemiology, pathogenicity, biofilm formation, natural antifungal products and new therapeutic options. Journal of Medical Microbiology.2013; 62 (1):10-24.

[4] Deorukhkar S and Saini S. Non albicans Candida species: its isolation pattern, species distribution, virulence factors and antifungal susceptibility profile. International Journal of Medical Science and Public Health. 2013; 2 (3): 533-538.

[5] Pandey A, department of microbiology. Neonatal Candidemia changing trend. Indian Journal of Pathology and Microbiology. 2012; 55(1).

[6] Segal E, Elad D. Candida species. In: Libero Ajello and Roderick J Hay editors, Topley and Wilson's Medical Mycology. Vol 4. $9^{\text {th }}$ edition, Oxford University press, New York. 1998; 423-460.

[7] Chander J. Text Book of Medical Mycology, 3rd edition. 2009; 20:274-279.

[8] Mackie TJ ; Collee JG; McCartney JE et al. Mackie and McCartney practical medical microbiology.2007; $14^{\text {th }}$ ed. Elsevier Publication.

[9] Hassan A, Usman J, Kaleem F et al. Evaluation of different detection methods of biofilm formation in the clinical isolates. Braz J Infect Dis. 2011; 15:305-11.

[10] Price MF, Wilkinson ID, Gentry LO. Plate method for detection of phospholipase activity in Candida albicans. Sabouraudia 1982; 20: 7-14.

[11] Samaranayake LP, Calman KC, Ferguson MM et al. The oral carriage of yeasts and coliforms in patients on cytotoxic therapy. Journal of Oral Pathology \& Medicine.1984; 13(4): 390-393.

[12] Manns JM, Mosser DM, Buckley HR. Production of hemolytic factor by Candida albicans. Infect Immun. 1994; 62: 5154-5156.

[13] Staib F. Serum-proteins as nitrogen source for yeast like fungi. Sabouraudia Journal of Medical andVeterinary Mycology. 1965;4(3)187-193.

[14] Negri M, Martins M, Henriques M et al. Examination of potential virulence factors of Candida tropicalis clinical isolates from hospitalized patients. Mycopathologia. 2010; 169(3):175-182

[15] Jarvis WR. Epidemiology of nosocomial fungal infections, with emphasis on Candida species. Clin Infect Dis. 1995; 20:1526-30.

[16] Pfaller MA, Houston A, Coffmann S. Application of CHROMagar Candida for rapid screening of clinical specimens for Candida albicans, Candida tropicalis, Candida krusei, and Candida (Torulopsis) glabrata. J Clin Microbiol. 1996 Jan;34(1):58-61.

[17] Roilides E, Farmaki E, Evdoridou J et al. Neonatal candidiasis: analysis of epidemiology, drug susceptibility, and molecular typing of causative isolates. Eur J Clin Microbiol Infect Dis. 2004; 23: 745750.

[18] Ariff S, Saleem AF, Soofi SB et al. Clinical spectrum and outcomes of neonatal candidiasis in a tertiary care hospital in Karachi, Pakistan. J Infect Dev Ctries. 2011; 5(3):216-223.

[19] S Narain. Neonatal systemic candidiasis in a tertiary care centre. Indian journal of medical microbiology. 2003; 21 (1): 56-58.
[20] Kaur R, Goyal R, Dhakad MS et al. Epidemiology and Virulence Determinants including Biofilm Profile of Candida Infections in an ICU in a Tertiary Hospital in India. Journal of Mycology.2014 ;14Article ID 303491, 8 pages.

[21] Kotwal A, Biswas D, Sharma JP,et al. An observational study on the epidemiological and mycological profile of Candidemia in ICU patients. Med Sci Monit. 2011; 17(11): 663-668.

[22] Shin JH, Kee SJ, Shin MG et al. Biofilm production by isolates of Candida species recovered from nonneutropenic patients: comparison of bloodstream isolates with isolates from other sources. Journal of Clinical Microbiology. 2002; 40 (4):1244-1248.

[23]Luo, G., L. P. Samaranayake, and J. Y. Y. Yau. Candida species exhibit differential in vitro hemolytic activities. J. Clin. Microbiol. 2001; 39: 2971 2974.

[24]Zaugg C, Zepelin BV, Reichard M et al. Secreted aspartic proteinase family of Candida tropicalis. Infect Immun. 2001; 69:405-412.

[25] Bramono K, Yamazaki M, Tsuboi R \& Ogawa, H. Comparison of proteinase, lipase and alpha-glucosidase activities from the clinical isolates of Candida species. Jpn J Infect Dis. 2006; 59:73- 76.

[26] Ingham CJ, Boonstra S, Levels $S$ et al.Rapid susceptibility testing and microcolony analysis of Candida spp. cultured and imaged on porous aluminum oxide.2012;1:45-9.

[27] Thangam M, Smitha S, Deivanayagam CN. Phospholipase activity of Candida isolates from patients with chronic lung disease. Lung India. 1989; 3:125-126.

[28] Changdeo S. Aher, Species ditribution, virulence factors and antifungal susceptibility profile of Candida isolated from Oropharyngeal lesions HIV infected paients .Int. J Cur Micobl. Ap Sci. 2014; 3(1): 453-460.

[29] Mohandas V and Ballal M. Proteinase and phospholipase activity as virulence factors in Candida species isolated from blood. Revista Iberoamericanade Micologia. 2008; 25 (4) 208-210.

[30] Jayatilake JA, Samaranayake YH, Cheung LA et al. Quantitative evaluation of tissue invasion by wild type, hyphal and SAP mutants of Candida albicans, and nonalbicans Candida species in reconstituted human oral epithelium. J Oral Pathol. 2006; 35:484-491. 